\title{
Microstructure by Thermal Attack under Vacuum of a Superduplex Stainless Steels and Electrochemical Behavior in $\mathrm{H}_{2} \mathrm{~S} / \mathrm{CO}_{2}$-Saturated Synthetic Seawater
}

\author{
Elki C. Souza, ${ }^{*, a}$ Carlos A. Fortulan ${ }^{b}$ and João M. D. A. Rollo \\ a Departamento de Química Ambiental, Universidade Federal do Tocantins (UFT), \\ 77402-970 Gurupi-TO, Brazil \\ ${ }^{b}$ Departamento de Engenharia Mecânica, Escola de Engenharia de São Carlos, \\ Universidade de São Paulo (USP), 13560-970 São Carlos-SP, Brazil \\ ${ }^{c}$ Departamento de Engenharia dos Materiais, Escola de Engenharia de São Carlos, \\ Universidade de São Paulo (USP), 13566-590 São Carlos-SP, Brazil
}

Superduplex stainless steels (SSS) composed in both equal fraction ferritic-austenite phases, classically defined by ASTM A995M Gr.5A, in order to obtain a better relation of mechanical properties and corrosion properties, are applied as components for use in petrochemical industries in off-shore platforms. The corrosion resistance of stainless steels is due to the oxides formed on the surface, which is dependent on the temperature and environment in which they are exposed. This paper investigates a microstructure duplex during steps of thermal attack under vacuum at high temperatures through observation of the coloration and growth of oxide films. Some coloration was observed in the phases, austenite and ferrite, with the increase of the temperature to $1100{ }^{\circ} \mathrm{C}$, which is indicative of the presence of chromium and iron oxides. In the cooling occurs the stability of oxides present in the films. Electrochemical tests were conducted in $\mathrm{H}_{2} \mathrm{~S} / \mathrm{CO}_{2}$-saturated in two different concentrations of chloride sodium electrolyte, simulating a seawater environment. Potentiodynamic polarization curves indicate that pitting corrosion resistance and repassivation process in media of 3.5 and $9.0 \%$ (wt. $\%$ ) $\mathrm{NaCl}$ are not affected by the presence of $\mathrm{H}_{2} \mathrm{~S} / \mathrm{CO}_{2}(40 / 60 \mathrm{ppm})$ at room temperature $\left(25^{\circ} \mathrm{C}\right)$.

Keywords: superduplex stainless steels, thermal attack under vacuum, oxide films, potentiodynamic polarization

\section{Introduction}

Austenitic-ferritic stainless steels (duplex and superduplex) are widely used in the manufacture of cast products, such as storage tanks, flow control valves, pipelines, centrifugal pumps, pressure vessels and reactors in petrochemical industries, and oil and gas exploration, in off-shore platforms. ${ }^{1-4}$ These stainless steels operating in a chloride environment, at high temperatures, exposed to $\mathrm{H}_{2} \mathrm{~S}$, $\mathrm{CO}_{2}$ and other dissolved corrosive agents, have combined good localized mechanical properties and higher crevice corrosion and pitting attack resistance. ${ }^{5,6}$

Duplex stainless steels are composed in two phases in comparable volume fractions of ferrite $(\delta)$ and austenite $(\gamma)$, based on the $\mathrm{Fe}-\mathrm{Cr}-\mathrm{Ni}$ system, containing other chemical elements classified as either ferrite $(\mathrm{Cr}, \mathrm{Mo}$,

*e-mail: elkicsouza@uft.edu.br
$\mathrm{Si}$ ) or austenite (Ni, N, C, Mn, Cu) stabilizers. ${ }^{4}$ When the pitting resistance equivalent number $(\mathrm{PREn}=\mathrm{wt} . \% \mathrm{Cr}+$ 3.3 wt. $\%$ Mo +16 wt. $\% \mathrm{~N}$ ) exceeds 40 , they are called superduplex stainless steels (SSS), ${ }^{7,8}$

The literature ${ }^{9}$ reports the effects of the chemical composition of passive films formed in both phases of two types of duplex stainless steel (UNS S31803 and UNS S32304) by using Auger electron spectroscopy (AES) and quantitative relationships between electrochemical parameters in sodium chloride media. The distribution of chromium and iron in the oxide layer was also found. ${ }^{9}$ The results confirm that nitrogen and nickel are mainly found in the austenite, whereas the ferrite is significantly enriched with chromium. This leads to a difference in the $\mathrm{Cr}$ content between the two phases of about $3 \mathrm{wt} . \%$. It can be mentioned that roughly the same value of the ratio $\mathrm{Cr} / \mathrm{Fe}$ in the passive film was found in the two phases ( 0.51 on the ferrite and 0.58 on the austenite). There is 
a linear relationship between the corrosion potential and the ratio $\mathrm{Cr} / \mathrm{Fe}$ in the passive film. It is interesting to note that the same evolution was found on various stainless steel microstructures, after different surface preparations and using several aqueous electrolytes. The corrosion potential becomes nobler by increasing the ratio $\mathrm{Cr} / \mathrm{Fe}$ in the passive film.

Many publications $s^{4,8,10-19}$ have described the use of electrochemical techniques for studying the electrochemical corrosion phenomenon, such as polarization and electrochemical impedance spectroscopy (EIS), which can investigate passive film resistance, the corrosion rate, and the behavior of coatings and inhibitors. Ge et al. ${ }^{16}$ have discussed, through polarization curve analysis and EIS data, the influence of sulfide on 316 stainless steel passive films. The authors concluded that the sulfide causes the passivity current of the stainless steel to increase. The Mott-Schottky plots indicated that, when the sulfide concentration increases, the slope of the straight segment, which reflects the properties of a p-type semiconductor (chromium oxide), decreases or even almost disappears. The slope of the straight segment, which reflects the properties of an n-type semiconductor (iron oxide), also decreases due to the influence of sulfide on the properties of the stainless steel passive film. ${ }^{16}$

Souza et al. ${ }^{10}$ studied the effect of chloride ion concentration and temperature on the corrosion resistance properties of an SSS containing approximately $50 \%$ of ferrite. The results indicate that the passive films formed are only slightly affected by chloride ion concentrations (5800; 22,700; 58,000 and 80,000 ppm of $\mathrm{Cl}^{-}$) at $25^{\circ} \mathrm{C}$, but the corrosion pitting resistance decreases drastically after potentiodynamic polarization at $78^{\circ} \mathrm{C}$, independently of chloride concentration. The analysis of the microstructure showed that the pitting number and size varied with the increase of the temperature of the tested medium and the Nyquist diagrams by EIS showed that the arc polarization resistance decreases as a function of the temperature, due to a catalytic degradation of the passive films. ${ }^{10}$ In another work, Souza et al. ${ }^{4}$ investigated the influence of ferrite phase content on the electrochemical properties of new SSS, with ferrite between 30 and $60 \%$, and their microstructure and corrosion resistance were evaluated by potentiodynamic polarization and EIS tests in $\mathrm{NaCl}$ $3.5 \%$ (wt.\%) at room temperature and $78{ }^{\circ} \mathrm{C}$. The results obtained at $25{ }^{\circ} \mathrm{C}$ showed that the pitting potential $\left(\mathrm{E}_{\mathrm{pit}}\right)$ is not significantly affected by the ferrite content, but for the materials with higher ferrite it was possible to observe an increase in the repassivation potential, with a decrease in the corrosion potential and passive currents due to the presence of more resistive passive films. Tests performed at $78^{\circ} \mathrm{C}$ indicated a significant decrease in the $\mathrm{E}_{\mathrm{pit}}$ for all the samples, independently of the ferrite percentage, although maintaining a superiority in higher ferrite content. Alloys with $55 \%$ ferrite phase content, i.e., less dependent of $\mathrm{Ni}$ element, present a superior performance in regard to corrosion resistance.

The present work focuses on the use of SSS with $50 \%$ ferrite and 50\% austenite for on-shore and off-shore applications. It is hypothesized that ferrite containing more chromium than austenite will have a higher formation of chromium oxide on its surface and also will be more resistant to corrosion. The localized corrosion resistance of an SSS in $\mathrm{H}_{2} \mathrm{~S} / \mathrm{CO}_{2}$-saturated synthetic seawater and oxide films on SSS are also investigated by electrochemical measurements and optical microscopy. This work also reports the change of coloration and the growth of different oxide films on a microstructure surface, which was revealed during steps of thermal attack under vacuum at high temperatures. The presence of a chromium element in the expression of greenish coloration was the discretization of the ferrite phase.

\section{Experimental}

\section{Sample preparation}

SSS ASTM A995M-Gr.5A/EN 10283-Mat\#1.4469 (GX2CrNiMo26-7-4) was prepared in an electrical induction furnace and submitted to heat treatment at $1100^{\circ} \mathrm{C}$ for $1 \mathrm{~h}$, followed by water quenching (to avoid the presence of deleterious phases in the microstructure, such as intermetallic or precipitates) ${ }^{4,10}$ The chemical composition (wt.\%), determined by optical emission spectrometry, the pitting resistance equivalent number, the percentage of magnetic phase (ferrite) using the ferritoscope magnetic and optical microscopy, for the SSS, are presented in Table 1.

The starting material chosen was steel defined by ASTM A995M Gr.5A and PRE $_{n}$ maximized, limiting the percentage of ferritic phase by $50 \%$, determined as a function of the ratio of $\mathrm{Cr}_{\text {equiv. }} / \mathrm{Ni}_{\text {equiv. }}$, in order to obtain a better relation of mechanical properties and corrosion properties.

\section{Electrochemical measurements}

Electrochemical analyses were carried out in a potentiostat/galvanostat (VoltaLab) model 402 with VoltaMaster 4 software for data acquisition. All electrochemical measurements were made using a threeelectrode system, consisting of a counter electrode of platinum wire, a saturated calomel electrode (SCE) as 
Table 1. Chemical composition, pitting resistance equivalent number $\left(\mathrm{PRE}_{\mathrm{n}}\right)$, percentage of ferrite (magnetic phase) estimated by ferritoscope and by optical microscopy (O.M.) for the SSS

\begin{tabular}{|c|c|c|c|c|c|c|c|c|}
\hline C / wt. \% & $\mathrm{Mn} / \mathrm{wt} . \%$ & $\mathrm{Si} / \mathrm{wt} . \%$ & P / wt. \% & S / wt. $\%$ & Cr/wt. $\%$ & $\mathrm{Ni} /$ wt. $\%$ & Mo / wt. \% & N/wt. \% \\
\hline 0.022 & 1.24 & 0.65 & 0.027 & 0.006 & 24.81 & 7.72 & 4.01 & 0.222 \\
\hline $\mathrm{PRE}_{\mathrm{n}}$ & & & & 41.6 & & & & \\
\hline Ferritoscope / \% & & & & 46.0 & & & & \\
\hline O.M. / \% & & & & 48.0 & & & & \\
\hline
\end{tabular}

$\mathrm{PRE}_{\mathrm{n}}=\% \mathrm{Cr}+3.3 \% \mathrm{Mo}+16 \% \mathrm{~N} \geq 40$.

reference and the SSS samples as working electrode (exposed area, $1 \mathrm{~cm}^{2}$ ), where Teflon O-rings were used in the sample-port to seal the part not exposed of SSS to the electrolyte.

The electrolyte media were 3.5 and $9.0 \%$ (wt.\%) $\mathrm{NaCl}$ without and with $\mathrm{H}_{2} \mathrm{~S} / \mathrm{CO}_{2}(40 / 60 \mathrm{ppm})$ at room temperature $\left(25^{\circ} \mathrm{C}\right)$. Seawater of Ipojuca-PE, Brazil was also used as electrolyte to compare with synthetic electrolyte (3.5\% $\mathrm{NaCl}$ ). In this environment, an average of about $35 \mathrm{~g}$ of salts were present for each kilogram of seawater, the majority being sodium chloride, i.e., a concentration of ca. $3.5 \%$ by weight $\mathrm{NaCl}$. The major solutes in seawater are in the form of cations and anions, and sodium $\left(\mathrm{Na}^{+}\right)$and chlorine $\left(\mathrm{Cl}^{-}\right)$, which constitute more than $85.65 \%$ (by weight) of all seawater substances. The six most important ions constitute more than $99 \%$ of all solutes. The most abundant ions present in seawater are: $\mathrm{Cl}^{-}, \mathrm{Na}^{+}, \mathrm{SO}_{4}{ }^{2-}, \mathrm{Mg}^{2+}, \mathrm{Ca}^{2+}$ and $\mathrm{K}^{+}$.

An electrochemical cell was used for open circuit potential (OCP) monitoring for $10 \mathrm{~h}$ and for potentiodynamic polarization curves obtained in these electrolytes. The potentiodynamic polarization measurements scanning were performed at $0.5 \mathrm{mV} \mathrm{s}^{-1}$ from $300 \mathrm{mV}$ below the OCP until above the pitting potential $v s$. SCE. The $\mathrm{E}_{\text {pit }}$ was defined when the current density exceeded $100 \mu \mathrm{A} \mathrm{cm} \mathrm{cm}^{-2}$. For the cyclic scans, the potential scan was reversed when the current reached $3 \mathrm{~mA} \mathrm{~cm}{ }^{-2}$. The passive current density $\left(\mathrm{i}_{\text {pass }}\right), \mathrm{E}_{\mathrm{pit}}$ and repassivation potential $\left(\mathrm{E}_{\mathrm{rep}}\right)$ were estimated from the polarization curves, and the corrosion potential $\left(E_{\text {corr }}\right)$ was obtained using the Tafel slopes method.

Metallographic apparatus for thermal attack under vacuum

The thermal attack under vacuum technique was used to reveal, at high temperatures, the duplex microstructure and to obtain the fraction and morphology of ferrite phase. The cylindrical samples, diameter $(4.2 \mathrm{~mm}) \times$ height $(5.0 \mathrm{~mm})$, with a plane face polished exposed to the camera, in hot-stage microscope in a high vacuum chamber (in the order of $10^{-5}$ Torr), were then subjected to heating at a rate of $10{ }^{\circ} \mathrm{C} \mathrm{min}-1$ to a maximum of $1100{ }^{\circ} \mathrm{C}$, staying as isothermal for $10 \mathrm{~min}$. Even at low oxygen concentration under vacuum, during heating, a thin layer of oxides formed on the surface of the sample characterized by the variation of the typical coloration of each oxide formed. This metallographic appearance of the microstructures due to thermal attack was observed by microscopy polarized light and the images of surface transformations were registered using a digital camera. The images were analyzed by Corel Photo-PaintTM X $8^{20}$ and Scion Image software. ${ }^{21}$ The system consist of an Aristomet microscope with digital acquisition of images that supports a heating chamber, Heating Stage 1750 (Leitz), that operates in a high vacuum (mechanical pump coupled to a turbomolecular bomb reaching $10^{-5}$ Torr). The microscope is an assembly with high temperature objectives $(50,100,200$ and 500x). The quartz glass window turntable over heating chamber permits under vacuum to dislodge the saturated (vapor deposition) window region. Microscope Heating Stage 1750 serves for the microscopic investigation of the structure and/or phase changes of polished products. In high vacuum, these reactions are observed at controlled heating and cooling temperatures. The microscope heating stage was designed for observations in incident light. ${ }^{22}$ Figure 1 illustrates the metallographic apparatus for thermal attack.

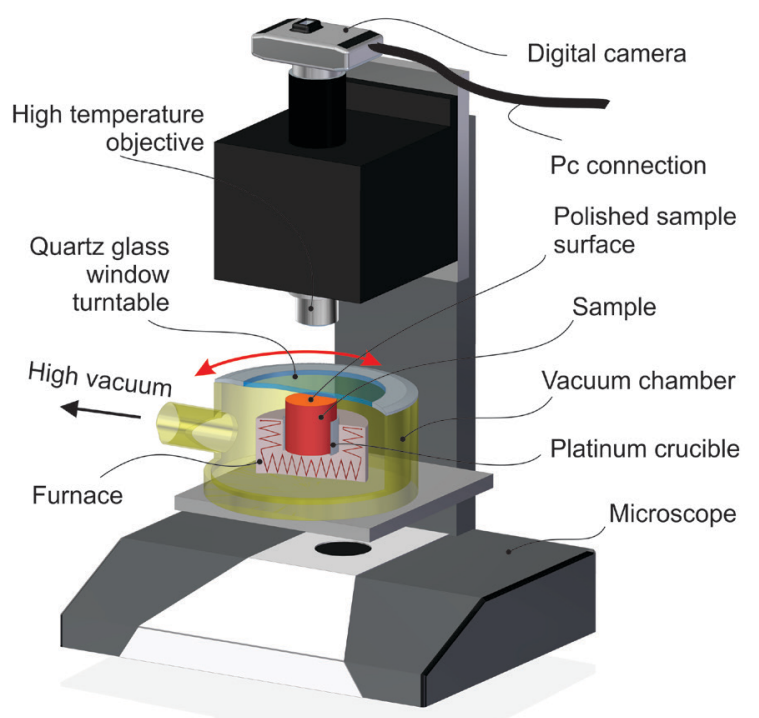

Figure 1. Illustration of apparatus for thermal attack under vacuum. 
Optical microscopy and scanning electron microscopy (SEM) analysis

After electrochemical tests, pits formation and their images were observed using optical microscopy. Analysis of the elements content in each phase was performed using Link Analytical EDS equipment (model QX 2000) coupled with a Zeiss SEM (model LEO 940A) to confirm the compositions in two present phases and to quantify the elements in the pit region.

\section{Results and Discussion}

\section{Microstructure for the SSS}

Figure 2 shows the SSS ASTM A995M Gr.5A in the polished state prior to any surface attack, showing a typical microstructure of an austenitic-ferritic matrix. It is possible to observe some inclusions due to the manufacturing process for this type of material.

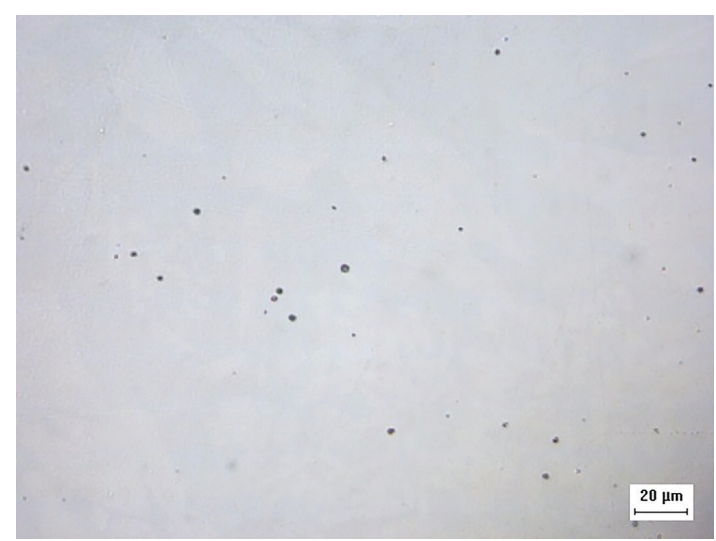

Figure 2. Typical microstructures of austenitic-ferritic steel without Beraha's etch. Dark spots are related to the inclusion of mixed precipitates. Microscopy magnification: 500x.

Figure 3 shows the microstructures revealed after Beraha's chemical etch for a typical cast microstructures of the SSS analyzed in four different microscopy magnifications. The duplex microstructure is composed of two phases: austenite (clear field), which presents elongated forms and transverse orientations, and ferrite (blue phase), represented by a matrix in the background. It is possible to observe (Figure 1d, highest magnification) that both phases present small inclusions.

Microstructure by thermal attack under vacuum at high temperature

A duplex stainless steel sample was heated under vacuum and two Vickers microhardness (HV) indentations

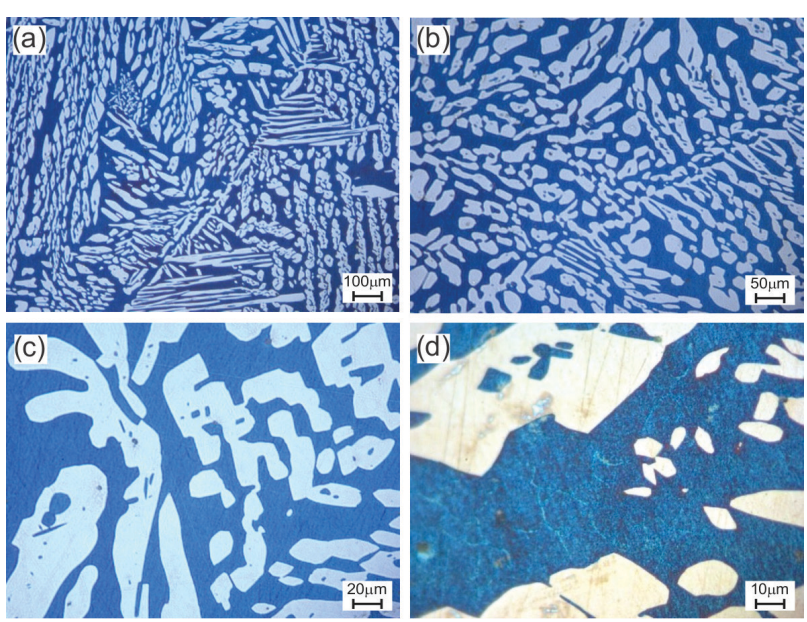

Figure 3. Microstructures of austenitic-ferritic steel SSS after Beraha's etch. Microscopy magnification: (a) 100x; (b) 200x; (c) 500x; (d) 1000×.

(load of $100 \mathrm{gf}$ ) were made on its surface to assist its positioning. High temperature metallography at low ultimate pressures excludes the formation of visible oxide films on their surfaces. However, these films are visible under the microscope. ${ }^{22}$ Figure 4 shows the different colorations of the microstructure of austenitic-ferritic stainless steel during the heating, isothermal and cooling steps under vacuum thermal attack.

The microstructure of duplex structure was investigated by the color change that began to be revealed at $500{ }^{\circ} \mathrm{C}$, as verified by the micrograph in Figure $4 \mathrm{~b}$ : it presents the typical appearance of the microstructure constituted by its distinct phases, austenite and ferrite. From a temperature of $750{ }^{\circ} \mathrm{C}$, a blue coloration was observed in the ferritic matrix, which may indicate the formation of chromium oxides. After $800^{\circ} \mathrm{C}$, a growth in the contour of the phases, austenite and ferrite, was evidenced. At $960{ }^{\circ} \mathrm{C}$, the orange color on the ferrite and red on the austenite were more intense. At near $1100{ }^{\circ} \mathrm{C}$, the pronounced presence of $\mathrm{Fe}_{2} \mathrm{O}_{3}$ (hematite) promoted color saturation, and was accentuated by helding of the plateau at this temperature for $10 \mathrm{~min}$. In the cooling, no significant changes were observed in the coloring of the material, showing the stability of the oxides present in the films.

In the literature, ${ }^{23}$ it is described that alloy steels containing a higher chromium content than $2 \%$ at pressure of $10^{-5}$ Torr show oxidation film. At temperatures exceeding $450{ }^{\circ} \mathrm{C}$, there will be a larger supply of chromium from the alloy bulk to the gas/oxide interface than of oxygen, and initially metallic chromium is present, but a pure chromium oxide is ultimately expected. ${ }^{23}$ Thus, more mobile iron will also segregate to the gas/oxide interface to react with oxygen during further oxidation. Hence, the film will become more enriched in iron. In the analysis, it becomes possible to gradually see the occurrence of the 

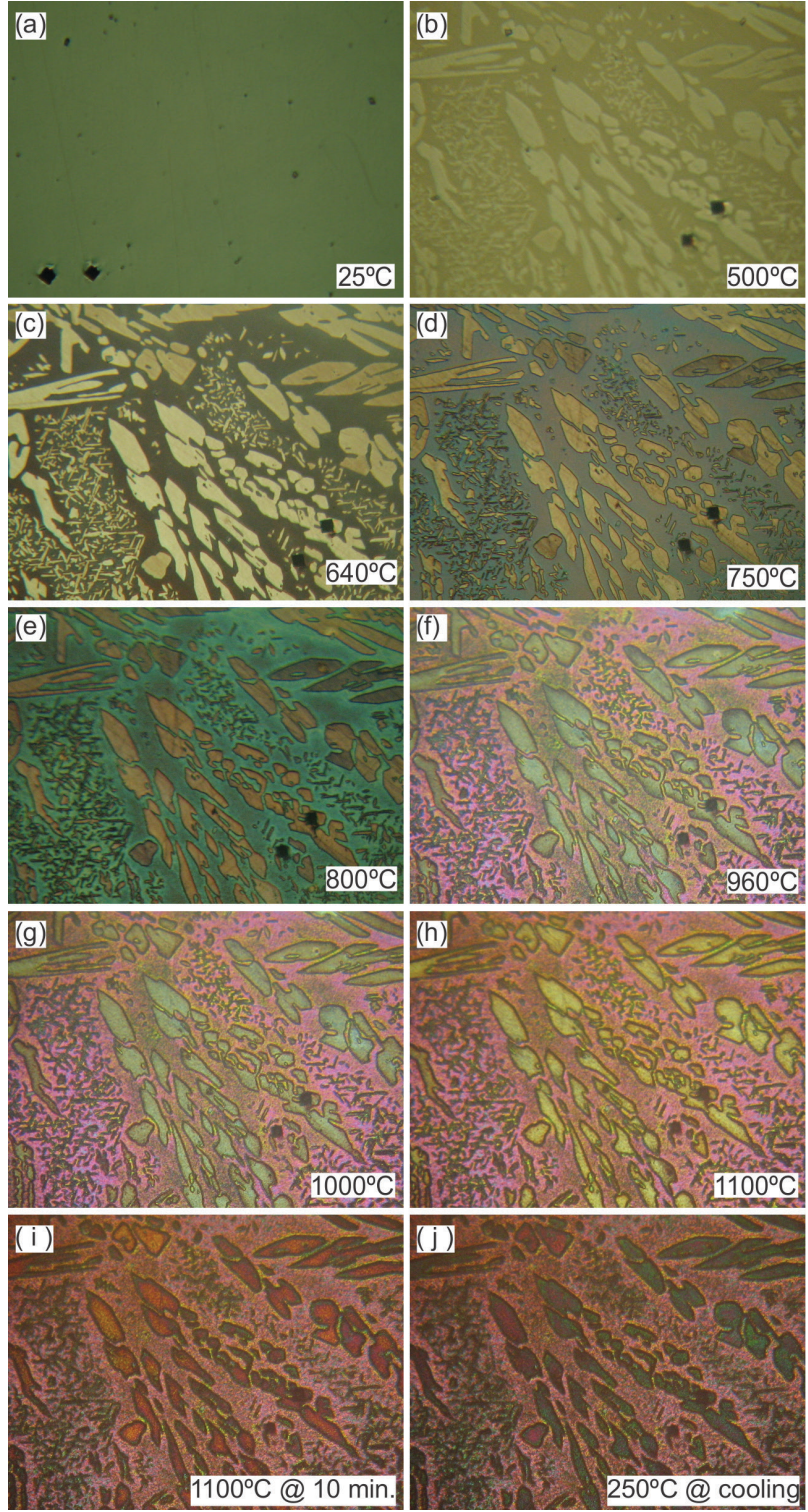

Figure 4. Photomicrographs of an austenitic-ferritic steel during (a-h) heating, (i) isothermal and (j) cooling steps, from room temperature $\left(25^{\circ} \mathrm{C}\right.$ ) to $1100{ }^{\circ} \mathrm{C}$. Thermal cycle: $10^{\circ} \mathrm{C} \mathrm{min}-1$ and isothermal of $10 \mathrm{~min}$. @ = plateau or followed.

phenomena of diffusion and oxidation in the surface..$^{23}$ The high resistance to corrosion and sorption is mainly attributed to the observed high chromium-enrichment in the surface film that occurs due to the flow of chromium at the earliest stages of oxidation, and for this, it is important to characterize the diffusion of chromium through the oxide to the gas/oxide interface. ${ }^{23}$ Diffusion studies of metals in stainless steel oxide or chromium oxide during oxidation have usually been carried out in high oxygen pressures and high temperatures, where oxidation-induced changes of the oxide film are conspicuous. However, in high pressure, it is known that there is an increase in chaotic motion where the molecules are colliding and exchanging energy. ${ }^{23}$ The majority of the phase diagrams of metals and alloys used in present-day engineering are constructed without the inclusions of the gas phase. Under the assumption that the equilibrium is independent of the vapor pressure of the components, this simplification gives an entirely satisfactory form of phase diagram for the solution of many practical problems and agrees with experimental data.

The presence of the colors that appear during the heating stage is indicative of the presence of oxides that vary in intensity with increasing temperature. Each phase shows the colors of the oxides formed, which may be related to the iron present in large quantities or the combination of this with the chromium. In general, the red color and its shades (brown, orange and pink) are due to the iron oxides $\left(\mathrm{Fe}_{2} \mathrm{O}_{3}\right.$, FeO, etc.) and also $\mathrm{CrO}_{3}$. The green color is attributed to the presence of $\mathrm{Cr}_{2} \mathrm{O}_{3}$.

\section{Electrochemical polarization curves}

Figure 5 shows the polarization curves obtained for the SSS tested in 3.5 and $9.0 \% \mathrm{NaCl}$ solution unsaturated and $\mathrm{H}_{2} \mathrm{~S} / \mathrm{CO}_{2}(40 / 60 \mathrm{ppm})$-saturated at $25^{\circ} \mathrm{C}$, and Table 2 presents the results from these curves: corrosion potential $\left(\mathrm{E}_{\text {corr }}\right)$, passivation current $\left(\mathrm{i}_{\text {pass }}\right)$, potential pit $\left(\mathrm{E}_{\text {pit }}\right)$ and repassivation potential $\left(\mathrm{E}_{\text {repass }}\right)$ values.

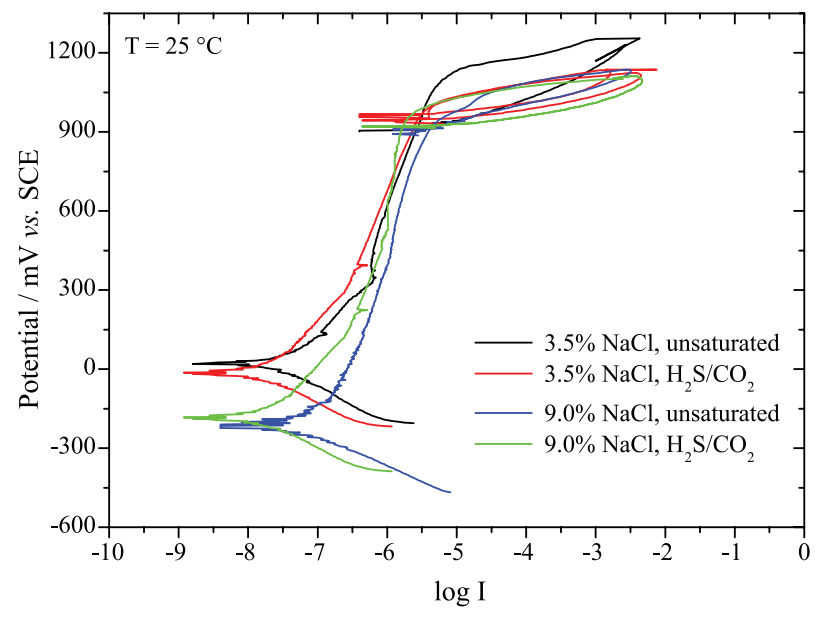

Figure 5. Potentiodynamic polarization curves for SSS in 3.5 and $9.0 \% \mathrm{NaCl}$ at room temperature: unsaturated $(\mathrm{pH}$ electrolyte $=5.5)$ and saturated with $\mathrm{H}_{2} \mathrm{~S}_{2} \mathrm{CO}_{2}: 40 / 60 \mathrm{ppm}(\mathrm{pH}$ electrolyte $=4.9)$. Potential scan rate: $0.5 \mathrm{mV} \mathrm{s}^{-1}$.

From the $\mathrm{E}_{\text {corr }}$ value, the current increases until it reaches a constant value of current density, installing the passivity, which is the range of potentials, higher or lower, where the current remains practically constant $\left(\mathrm{i}_{\text {pass }}\right)$. The passive film formed on the surface of the material has insulating or semiconducting characteristics. Afterwards, at higher 
Table 2. Electrochemical parameters estimated from polarization curves at room temperature

\begin{tabular}{|c|c|c|c|c|c|}
\hline Electrolyte & & $\mathrm{E}_{\text {corr }} / \mathrm{mV}$ & $\mathrm{i}_{\text {pass }} /\left(\mu \mathrm{A} \mathrm{cm} \mathrm{cm}^{-2}\right)$ & $\mathrm{E}_{\mathrm{pit}} / \mathrm{mV}$ & $\mathrm{E}_{\text {repass }} / \mathrm{mV}$ \\
\hline \multirow[t]{2}{*}{$\mathrm{NaCl} 3.5 \%$} & unsaturated & 26 & 6.3 & 1100 & 945 \\
\hline & $\mathrm{H}_{2} \mathrm{~S}_{/ \mathrm{CO}_{2}}(40 / 60 \mathrm{ppm})$ & -14 & 6.2 & 1020 & 950 \\
\hline \multirow[t]{2}{*}{$\mathrm{NaCl} 9.0 \%$} & unsaturated & -203 & 5.9 & 990 & 915 \\
\hline & $\mathrm{H}_{2} \mathrm{~S}_{/ \mathrm{CO}_{2}}(40 / 60 \mathrm{ppm})$ & -185 & 6.0 & 1000 & 920 \\
\hline
\end{tabular}

$\mathrm{E}_{\text {corr }}:$ corrosion potential; $\mathrm{i}_{\text {pass }}:$ passivation current; $\mathrm{E}_{\text {pit }}$ p potential pit; $\mathrm{E}_{\text {repass }}:$ repassivation potential.

potentials, a new increase of the current occurs. This may be due to several phenomena, such as the establishment of the localized corrosion (pit), for example.

From the polarization curves shown in Figure 5, it can be suggested that the passive film prevents metal corrosion up to a certain value of electrochemical potential: close to $1.0 \mathrm{~V}$ for all solutions (at two $\mathrm{NaCl}$ concentrations studied, unsaturated and gas mixture-saturated electrolyte) tested at $25{ }^{\circ} \mathrm{C}$. From the corrosion potential, the anodic process starts slowly (larger range potential), the passive film with pseudo-passive characteristic (semiconductor) loses electrical resistance, allowing the ionic diffusion, until the pitting potential is reached.

The results for the SSS electrode submitted to the tests in saturated $\mathrm{H}_{2} \mathrm{~S} / \mathrm{CO}_{2}$ chloride medium shows that there are no changes in the current passivation, pit and repassivation potentials when compared to the same unsaturated $\mathrm{NaCl}$ concentration. However, a small variation in corrosion potential was observed due to the presence of $\mathrm{H}_{2} \mathrm{~S} / \mathrm{CO}_{2}$ in $\mathrm{NaCl} 3.5 \%$. The surface state may change the corrosion potential values; however, for all samples studied, the polarization tests were carried out under the same electrode surface finishing conditions. In the absence and presence of $\mathrm{H}_{2} \mathrm{~S} / \mathrm{CO}_{2}$ and at high concentrations of $\mathrm{NaCl}$, no significant changes were observed in the electrochemical parameters. It is seen that the pit corrosion resistance of the SSS is little or not at all affected by the presence of the gaseous mixture at room temperature. In order to compare the electrochemical behavior of the SSS sample in a non-simulated environment, seawater of Ipojuca-PE, Brazil, was used as electrolyte to compare with the synthetic electrolyte $(3.5 \% \mathrm{NaCl})$. The electrochemical test results for SSS show that in $\mathrm{NaCl}$ $3.5 \%$, non-saturated, the pit and repassivation potential values were 1.10 and $0.95 \mathrm{~V}$, respectively (Table 2), while they were 1.00 and $0.91 \mathrm{~V}$, respectively, using the seawater as electrolyte. It was observed that the ions present in the seawater did not influence the pitting and repassivation potential for the sample under these test conditions (at room temperature). These reports seem to indicate that temperature is the main factor that causes a decrease in $\mathrm{E}_{\text {pit }}$ and $\mathrm{E}_{\text {repass }}$, which can be accentuated by the presence of a mixture of corrosive gases. For the tests carried out at different temperatures in an unsaturated medium of $\mathrm{NaCl}$, the critical pitting temperature was $\mathrm{T}>60^{\circ} \mathrm{C}$, as already discussed in another study by Souza et al. ${ }^{10}$

Carbon dioxide is only corrosive in the presence of free water, when it is dissolved, giving rise to carbonic acid:

$$
\mathrm{CO}_{2}+\mathrm{H}_{2} \mathrm{O} \rightleftharpoons \mathrm{H}_{2} \mathrm{CO}_{3}
$$

When carbon dioxide $\left(\mathrm{CO}_{2}\right)$ is absorbed by seawater, chemical reactions occur, reducing the seawater $\mathrm{pH}$ and increasing the carbonate ion concentration. These chemical reactions are termed as "ocean acidification". Thus, the formation of carbonic acid $\left(\mathrm{H}_{2} \mathrm{CO}_{3}\right)$ lowers the $\mathrm{pH}$ of the water, increasing its corrosive characteristic. The main factors that influence the solubility of $\mathrm{CO}_{2}$ are pressure, temperature and water composition (dissolved mineral salts). The increase in the solubility of $\mathrm{CO}_{2}$ in water is directly proportional to the increase in pressure and inversely proportional to the increase in temperature. The mineral salts contained in the water can prevent the $\mathrm{pH}$ reduction. In reservoirs that produce natural gas, condensate and water with small percentages of mineral salts, pressure becomes the main factor controlling $\mathrm{CO}_{2}$ solubility. For this reason, the partial pressure of $\mathrm{CO}_{2}$ in the gas mixture can be used to determine the degree of corrosivity of electrolyte environments.

The hydrogen sulfide gas is soluble in water, forming a weak acid that can cause corrosion and contributes to the entrance of atomic hydrogen inside the metals. The overall reaction for this type of corrosion can be represented by the equation 2 :

$\mathrm{H}_{2} \mathrm{~S}+\mathrm{Fe}+\mathrm{H}_{2} \mathrm{O} \rightarrow \mathrm{FeS}+2 \mathrm{H}^{+}+\mathrm{H}_{2} \mathrm{O}$

The ferrous sulfide produced by this reaction generally adheres to the surface of the steel as a black powder or incrustation (FeS). It can act as a cathode on the steel surface, leading to a localized corrosion-type pit. However, the presence of the gas mixture $\mathrm{H}_{2} \mathrm{~S} / \mathrm{CO}_{2}$ did not bring noticeable changes in the electrochemical behavior for the sample studied at room temperature. 
Micrographics of the SSS after electrochemical tests at $\mathrm{T}>70^{\circ} \mathrm{C}$

Figures $6 \mathrm{a}-6 \mathrm{c}$ show the optical micrograph of SSS after polarization test in $3.5 \% \mathrm{NaCl}$ at $70{ }^{\circ} \mathrm{C}$, revealing the sites pitting formation according to Souza et al.,${ }^{10}$ who observed an increase in the numbers and sizes of pits when the temperature is above $70{ }^{\circ} \mathrm{C}$. At temperatures above $78^{\circ} \mathrm{C}$ in $9.0 \% \mathrm{NaCl}$, the micrograph (Figure $6 \mathrm{~d}$ ) shows cracking propagation. At temperatures below $60^{\circ} \mathrm{C}$ in $3.5 \% \mathrm{NaCl}$, the presence of cracking is not observed. This fact seems to indicate some intrinsic relation between the critical temperature of repassivation (or non-repassivation) and the appearance of cracking corrosion for all materials investigated. According to Petrobras standard, ${ }^{2}$ there are restrictions on the use of this class of material ${ }^{2,10}$ in chloride concentrations above $6.0 \%$ at temperatures above $60{ }^{\circ} \mathrm{C}$.
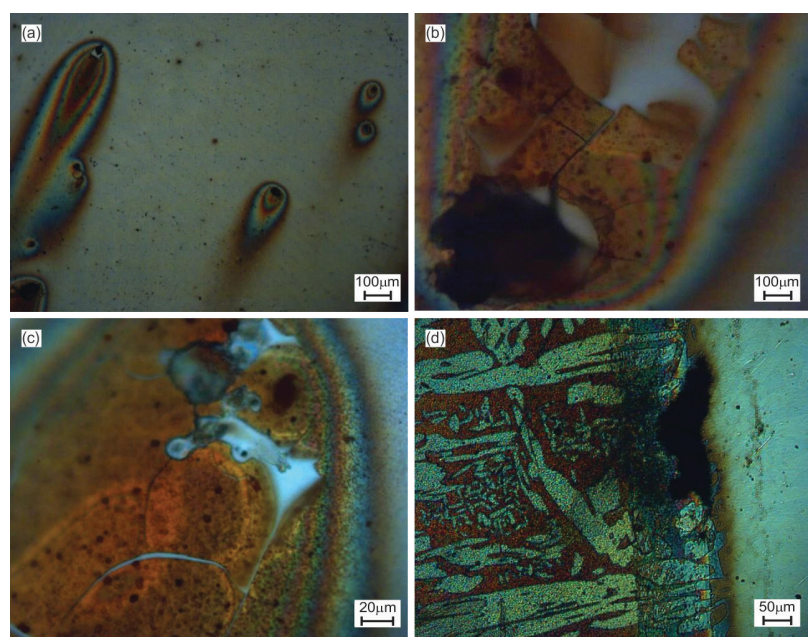

Figure 6. Optical micrograph of the SSS after polarization test in $3.5 \%$ $\mathrm{NaCl}$ at $70^{\circ} \mathrm{C}$, revealing the sites (a-c) pitting formation, and the colors of the corrosion products; (d) cracking propagation at $78^{\circ} \mathrm{C}$ in $9.0 \% \mathrm{NaCl}$.

Figures $6 \mathrm{a}, 6 \mathrm{~b}$ and $6 \mathrm{c}$ reveal the corrosion products with different colors that are due to oxidation processes. In anodic reaction, iron is oxidized, and in the cathodic reaction the hydroxyl is formed from the dissolved oxygen in the solution:

$$
\begin{aligned}
& \mathrm{Fe} \rightarrow \mathrm{Fe}^{2+}+2 \mathrm{e}^{-} \\
& \mathrm{O}_{2}+2 \mathrm{H}_{2} \mathrm{O}+4 \mathrm{e}^{-} \rightarrow 4 \mathrm{OH}^{-}
\end{aligned}
$$

The two reactions occur simultaneously due to the passage of the electrical current through the metal from the region where the metal dissolution (anodic region) occurs to a region where the oxygen is reduced (cathodic reaction). The reactions 3 and 4, due to electron transfer, are of electrochemical nature, however, non-electrochemical reactions can proceed and may result in another corrosion products. Another consequence of the two basic electrochemical reactions is a precipitation of a brown product. This is an end product of the corrosive process better known as rust, that has a complex composition, but basically consist of compounds of the form $\mathrm{FeOOH}$ and/or $\mathrm{Fe}_{3} \mathrm{O}_{4} \cdot{ }^{19}$

\section{Energy dispersive X-ray (EDS) analyses}

Table 3 shows the semi-quantitative chemical composition obtained by EDS of the elements present in the different phases of SSS and in the pit region, along with the results of the chemical analysis for comparison. The energy characteristic of each element by the EDS analysis showed that iron (balance) is the major element of the alloy followed by $\mathrm{Cr}, \mathrm{Ni}, \mathrm{Mo}$ and $\mathrm{Mn}$. However, some elements have very close energies or are present in small concentrations, being, therefore, difficult to be identified.

In Figure 2, it is noted that the alloy presents darker points through the optical micrograph due to the presence of inclusions. The EDS analyses performed in the inner region within the pits on the SSS after the polarization tests showed high $\mathrm{Mn}$ and $\mathrm{Si}$ content, indicating that nucleation and propagation of the pits occurred in regions of inclusions/ mixed precipitates containing these two elements, probably $\mathrm{MnS} / \mathrm{SiO}_{2}$. It is known that pitting corrosion usually begins in regions of defects on the passive film, generally associated with the presence of sulfide inclusions..$^{24,25}$

\section{Conclusions}

The microstructure duplex was revealed at $500{ }^{\circ} \mathrm{C}$ by thermal attack under vacuum at high temperature and, with

Table 3. Chemical composition obtained by EDS for SSS (50\% ferrite). The result of the chemical analysis obtained by spectrometry is presented for the

\begin{tabular}{|c|c|c|c|c|c|c|}
\hline Element & Cr/wt.\% & $\mathrm{Ni} /$ wt. $\%$ & Mo / wt. \% & Mn / wt. $\%$ & $\mathrm{Si} / \mathrm{wt} \%$ & $\mathrm{Fe} / \mathrm{wt} . \%$ \\
\hline Ferrite $(\alpha)$ & 27.83 & 6.03 & 4.62 & 1.29 & 0.65 & 59.58 \\
\hline Austenite $(\gamma)$ & 24.57 & 9.51 & 2.05 & 1.47 & 0.58 & 61.82 \\
\hline Chemical composition $(\alpha+\gamma)$ & 24.81 & 7.72 & 4.01 & 1.24 & 0.65 & 61.57 \\
\hline Austenite + ferrite $(\alpha+\gamma)$ & 26.06 & 7.81 & 2.99 & 1.50 & 0.66 & 60.98 \\
\hline Pit & 28.42 & 3.62 & 0.91 & 28.48 & 10.79 & 27.78 \\
\hline
\end{tabular}
purposes of comparison 
the increase of temperature, some coloration was observed in both phases, austenite and ferrite, with the growth in the contour of the phases after $800{ }^{\circ} \mathrm{C}$ indicate the presence of chromium and iron oxides that varies in intensity with increasing temperature up to $1100{ }^{\circ} \mathrm{C}$. In the cooling step, no significant changes were observed in the coloring of the sample, indicating the stability of the oxides present in the films.

The electrochemical parameters by polarization curves indicate that the presence of the gas mixture did not bring noticeable changes in pitting and repassivation potentials values for the sample studied at room temperature. The pits formed on the SSS after the polarization tests showed high Mn and Si content by EDS analysis, indicating that nucleation and propagation of the pits occurred in regions of inclusions/mixed precipitates.

\section{Acknowledgments}

The authors acknowledge Fundação de Amparo à Pesquisa do Estado de São Paulo (FAPESP) for its technical and financial support for this research (No. 06/55579-0) and the Group Metal - Stainless Steel and Special Alloys for the manufacture of stainless steels.

\section{References}

1. Bettini, E.; Kivisakk, U.; Leygraf, C.; Pan, J. S.; Electrochim. Acta 2013, 113, 280.

2. Petrobras; Especificação Técnica No. ET-3000.00-1200-200PCI-001, Revisão G, Especificação de Engenharia ET 200.03, Materiais de Tubulação para Instalações de Produção e Facilidades de Processo, folha 05, 2007.

3. Bhattachatya, A.; Singh, P. M.; Corrosion 2008, 64, 532.

4. Souza, E. C.; Rossitti, S. M.; Fortulan, C. A.; Rollo, J.; Mater. Res. 2017, 20, 21.

5. Craidy, P.; Briottet, L.; Santos, D.; Int. J. Hydrogen Energy 2015, 40, 170840.

6. Antony, P. J.; Chongdar, S.; Kumar, P.; Raman, R.; Electrochim. Acta 2007, 52, 3985.
7. Gunn, R. N.; Duplex Stainless Steels: Microstructure, Properties and Applications; Elsevier: Cambridge, 1997.

8. Paulraj, P.; Garg, R.; Eng. Sci. Technol. Int. J. (JESTECH) 2016, 19, 1076.

9. Vignal, V.; Delrue, O.; Heintz, O.; Peultier, J.; Electrochim. Acta 2010, 55, 7118.

10. Souza, E. C.; Rossitti, S. M.; Rollo, J.; Mater. Charact. 2010 , $61,240$.

11. Luo, H.; Li, X. G.; Dong, C. F.; Xiao, K.; Arabian J. Chem. 2017, 10, S90.

12. Li, H. B.; Jiang, Z. H.; Feng, H.; Wang, Q.; Zhang, W.; Fan, G. W.; Li, G. P.; Wang, L. Y.; Int. J. Electrochem. Sci. 2015, 10, 1616.

13. Moura, V. S.; Lima, L. D.; Pardal, J. M.; Kina, A. Y.; Corte, R. R. A.; Tavares, S. S. M.; Mater. Charact. 2008, 59, 1127.

14. Komatsu, D.; Souza, E. C.; de Souza, E. C.; Canale, L. D. F.; Totten, G. E.; J. Mech. Eng. 2010, 56, 121.

15. Bastos, I. N.; Tavares, S. S. M.; Dalard, F.; Nogueira, R. P.; Scr. Mater. 2007, 57, 913.

16. Ge, H. H.; Zhou, D. D.; Wu, W. Q.; Appl. Surf. Sci. 2003, 211, 321.

17. Orazem, M. E.; Tribollet, B.; Electrochemical Impedance Spectroscopy, $2^{\text {nd }}$ ed.; Wiley: Hoboken, 2017.

18. Ebrahimi, N.; Momeni, M.; Kosari, A.; Zakeri, M.; Moayed, M. H.; Corros. Sci. 2012, 59, 96.

19. Wolynec, S.; Técnicas Eletroquímicas em Corrosão; Edusp: São Paulo, 2003, p. 162.

20. Corel Photo-PaintTM X8, v18.1.0.661, Corel Corporation: Ottawa, 2016.

21. Scion Image Software, v4.0.2, Scion Corporation: Frederick, 2000.

22. Lozinskii, M. G.; High Temperature Metallography; Pergamon: New York, 1961.

23. Cho, B.; Moon, S.; Chung, S.; Kim, K.; Kang, T.; Koo, B.; J. Vac. Sci. Technol., A 2001, 19, 998.

24. Geng, S. N.; Sun, J. S.; Guo, L. Y.; Wang, H. Q.; J. Manuf. Processes 2015, 19, 32.

25. Rhode, S.; Kain, V.; Raja, V. S.; Abraham, G. J.; Mater. Charact. 2013, 77, 109. 